\title{
Hippocampal lesions: Effects on memory in rats'
}

CHARLES G. GROSS, PETER BLACK, Harvard University, Cambridge, Mass. 02138, and STEPHAN L. CHOROVER, Massachusetts Institute of Technology, Cambridge, Mass. 021.39

Frequency of spontaneous alternation in a T-maze as a function of intertrial interval was determined for rats with dorsal hippocampal lesions and for controls. The slopes of these two functions were identical, but the curve for the animals with the hippocampal lesions had a lower $y$ intercept, suggesting that hippocampal lesions impair learning rather than forgetting.

Rats with bilateral hippocampal lesions acquire several types of maze discrimination and avoidance habits more slowly than normal rats (Douglas, 1967). This might be so because rats with hippocampal lesions (a) learn less on each trial, (b) forget what they have learned more rapidly after each trial, or (c) both. In the present experiment, the phenomenon of "spontaneous alternation" is used to explore these possibilities.

Spontaneous alternation refers to an animal's tendency to alternate left and right choices on successive trials in a T-maze. The probability of alternation declines as the interval between trials increases, reaching chance levels at intervals of several hours (Walker, 1956). Several studies have shown that hippocampal lesions reduce spontaneous alternation (Roberts et al, 1962; Lash, 1964; Douglas \& Isaacson, 1964; Kirkby et al, 1967).

If the acquisition deficit following hippocampal lesions is due to less learning on each trial, then the function relating probability of alternation to intertrial interval should have a lower $y$ intercept but the same slope after hippocampal lesions. By contrast, if the deficit is due to more rapid forgetting after each trial, then the function should have the same $y$ intercept but a steeper slope after hippocampal lesions. Finally, if the deficit is due to both less learning and more rapid forgetting, a function with a lower $y$ intercept and a steeper slope would be expected to follow the lesions.

\section{METHOD.}

Seventy-one Long-Evans hooded rats weighing 200-300 g were used. Sixteen received bilateral hippocampal lesions made by aspiration through the overlying cortex. Figure 1 shows that these lesions were primarily confined to the dorsal aspect of the hippocampus. Twenty-five animals received bilateral cortical lesions approximating the cortical area destroyed in making the hippocampal lesions (Fig. 1). Thirty rats served as unoperated controls.

The apparatus was a T-maze with walls 11 in. high. The startbox (4 in. $x 6.5 \mathrm{in}$.) was separated by a sliding door from the stem (4 in. $x 13$ in.). The floor and walls of the startbox and stem were white. Each arm led to a goal box (63 sq in.). The arms ( 3.25 in. $x$ 19.5 in.) could be separated from the stem by a sliding door. A different black and white pattern covered the walls and floors of each arm and its associated goal box and the goal boxes were of different shapes. The maze was kept uncovered and remained in a

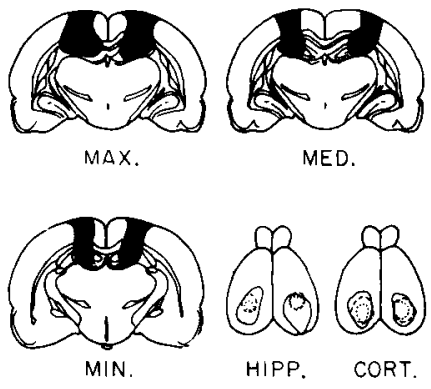

Fig. 1. Cross sections through the maximum, median and minimal hippocampal lesions and composite drawings showing the maximum, median and minimal extents of the cortical lesions for both the hippocampal and cortical groups.

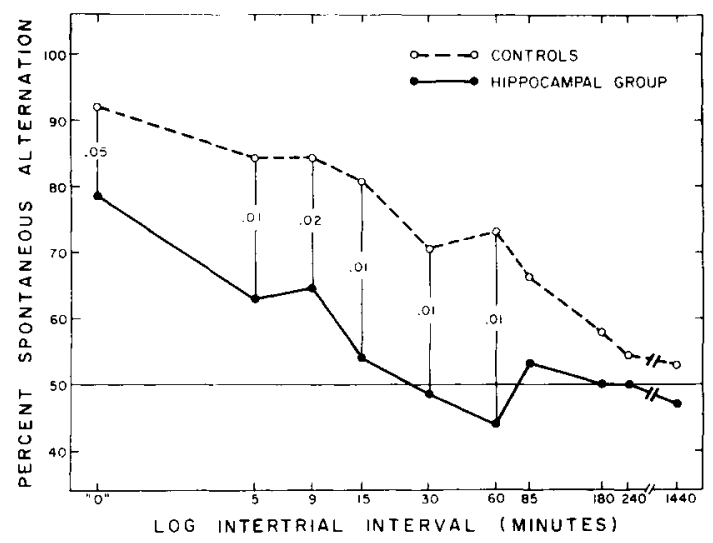

Fig. 2. Per cent alternation on the second trial as a function of $\log$ intertrial time. The numbers are significance levels for the difference between the groups at each intertrial interval according to a $\mathrm{X}^{2}$ test.

constant position in the test room. Neither goal box ever contained food.

The animals were deprived of food for 20-23.5 h before the first trial each day. They were fed for $30 \mathrm{~min} 0-3.5 \mathrm{~h}$ after the second trial each day. Only two trials were run per day. The intertrial intervals were $0,5,9,15,30,60,90,180^{\circ} \mathrm{min}$ and were presented in a predetermined randomized order. A $24 \mathrm{~h}$ point was obtained by treating the second trial of each day as "Trial 1" and the first trial of the following day as "Trial 2." On each trial, the rat was removed from its home cage and placed in the startbox. Ten sec later, the startbox door was opened. When the animal entered the left or right arm, the door connecting that arm to the stem was closed. The rat remained in the arm (or its associated goal box) for $1 \mathrm{~min}$ before either being replaced in the startbox (under the 0 min intertrial condition) or being returned to its home cage (under all other conditions).

\section{RESULTS AND DISCUSSION}

On the first trial, no group showed more than a $4 \%$ preference for either arm. At every delay interval, the frequency of alternation by cortical operates and unoperated controls was virtually equal. Therefore, their data were combined to provide a single control group. At the shortest intertrial interval, the animals with hippocampal lesions alternated significantly less than the controls and this difference between the groups remained similar until the performance of both groups fell to a chance level (Fig. 2 ). The running time for the groups did not differ. There was no relation between extent of lesion and performance within either operated group.

The results suggest that the experimental group acquired less information on the first trial, but lost it in the intertrial interval at the same rate as the controls. (A similar conclusion was reached by Kirkby et al, 1967.) That is, the animals with hippocampal lesions seemed to show deficient learning but normal forgetting. We conclude that the acquisition deficit that follows hippocampal lesions may be adequately accounted for without postulating an interference with "memory storage." This may also be true for the "amnestic" syndrome that follows hippocampal damage in man (Milner, 1959).

\section{REFERENCES}

DOUGLAS, R. J. The hippocampus and behavior. Psychological Bulletin, $1967,67,416442$.

DOUGLAS, R. J., \& ISAACSON, R. L. Hippocampal lesions and activity. Psychonomic Science, 1964, 1, 187-188.

KIRKBY, R. J., STEIN, D. G., KIMBLE, R. J., \& KIMBLE, D. P. Effects of hippocampal lesions and duration of sensory input on spontaneous 
alternation. Joumal of Comparative \& Physiological Psychology, 1967, 64, 342-345.

LASH, L. Response discriminability and the hippocampus. Journal of Comparative \& Physiological Psychology, 1964, 57, 251.256.

MILNER, BRENDA. The memory defect in bilateral hippocampal lesions. Psychiatric Research Reports, 1959, 11, 43-52.

ROBERTS, W. W., DEMBER, W. N., \& BRODWICK, M. Alternation and exploration in rats with hippocampal lesions. Journal of Comparative \&
Physiological Psychology, 1962, 55, 695-700.

WALKER, E. L. The duration and course of the reaction decrement and the influence of reward. Journal of Comparative \& Physiological Psychology, $1956,49,167-176$.

NOTE

1. This research was supported by N.I.H. Grants MH-07923 and MH-14471, and N.S.F. Grants GB-4104 and GB-6999. Miss Anne Marie DeLuca was invaluable at all stages of this study. 